\title{
Notes on the vocalizations of Rufous Gnateater (Conopophaga lineata)
}

Peter Boesman

In the following we briefly analyze and compare voice of the different races of Rufous Gnateater (Conopophaga lineata). We also try to quantify the extent of any vocal differences using the criteria proposed by Tobias et al. (2010), as a support for taxonomic review. We have made use of sound recordings available on-line from Xeno Canto (XC) and on commercial publications (Isler et al. 2002).

Song is a sweet series of notes, especially rising in pitch towards the end, with seemingly quite some variation. We made some measurements of basic sound parameters:

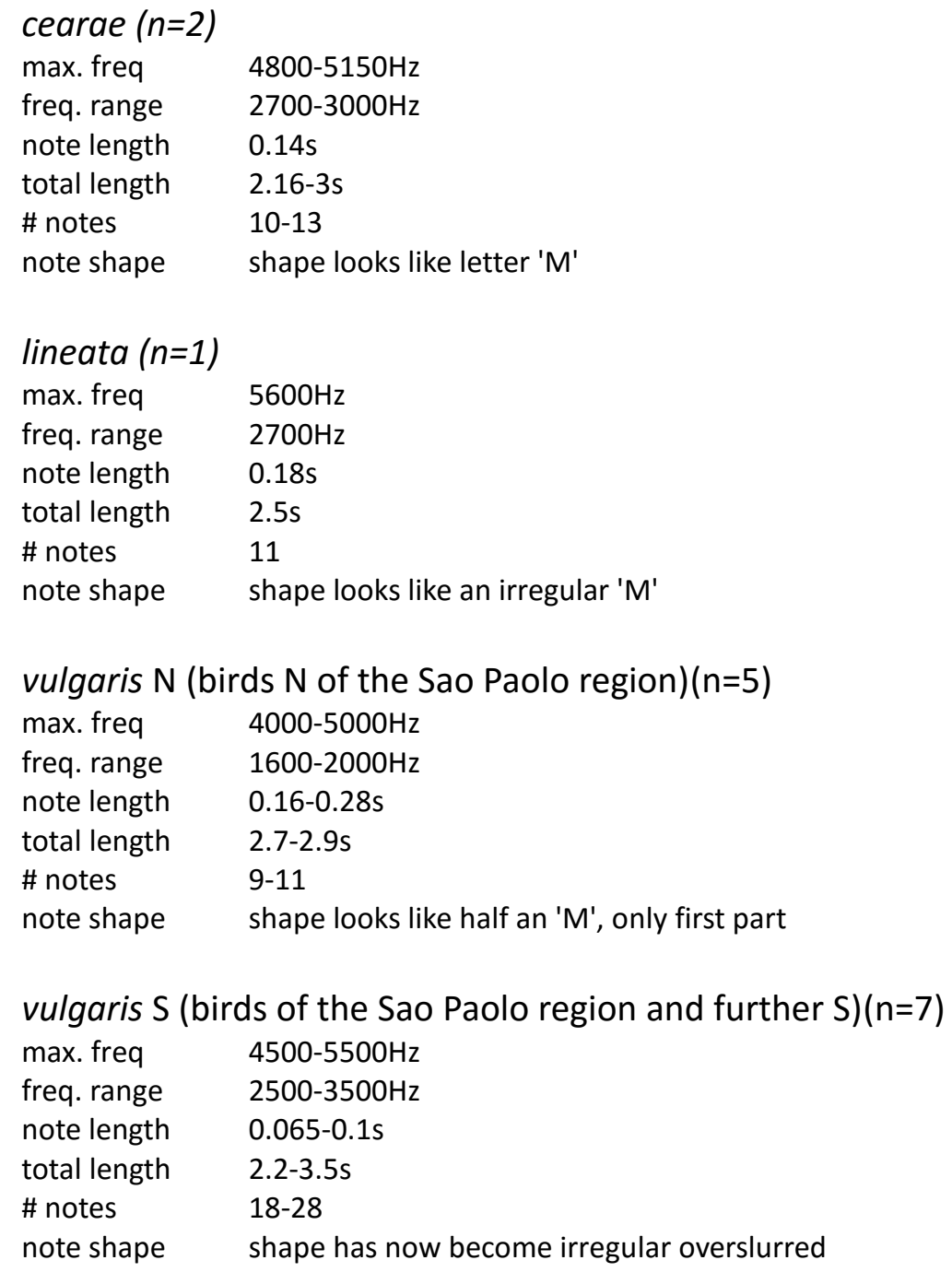




\section{HANDBOOK OF THE \\ BIRDS PF/THE WORLD}

\section{ORNITHOLOGICAL NOTES}

If we look at note shape there is a very gradual change in shape from $\mathrm{N}$ to $\mathrm{S}$, with cearae and lineata similar, and lineata similar to northern vulgaris (Fig 1.), and an abrupt change with southern vulgaris.
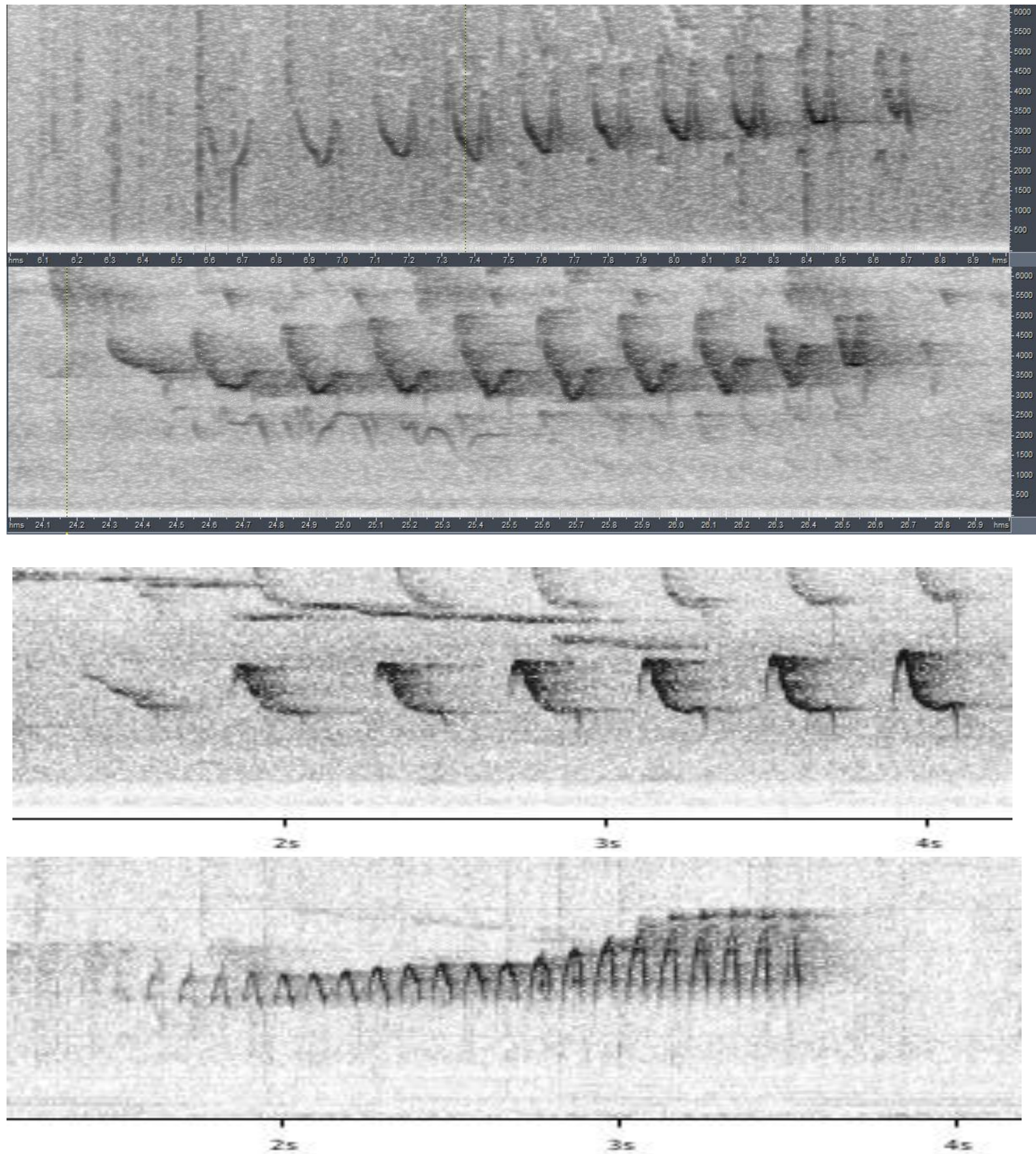

Figure 1: From top to bottom: cearae, lineata, vulgaris (N), vulgaris (S) 

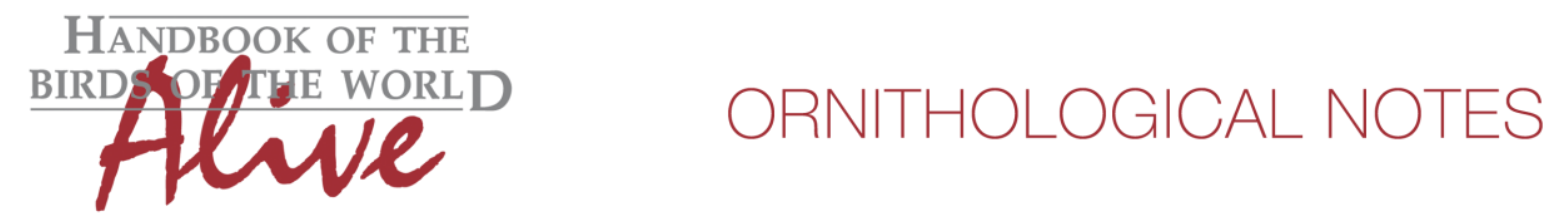

With only a few recordings of cearae and lineata available, we can't rely a lot on the measurements, but the least one can say is that differences between cearae, lineata and northern vulgaris are not striking at all. We don't even have recordings of song from the Recife population, which is located in between cearae and lineata. It is therefore surprising that some authorities elevated cearae to species rank to a large extent based on presumed vocal difference.

Based on the limited information we have available, it would seem that the score for vocal difference between cearae and lineata/northern vulgaris will be low (e.g. score 1 at most for note shape and score 1 for e.g. frequency range or note length), reflecting a minor vocal difference and rather just one extreme of a gradual change in loudsong from north to south.

Much more striking however is the vocal difference of southern birds of race vulgaris vs. all others, including northern birds of the same race vulgaris. There seems to be a fairly abrupt change in voice just north of Sao Paulo city. Note length, pace and number of notes are clearly different and would all score 2 or 3 , leading to a score of about 5 . This is an indication that vulgaris may comprise two different taxa.

This note was finalized on 13th May 2015, using sound recordings available on-line at that moment. We would like to thank in particular the sound recordists who placed their recordings for this species on XC.

\section{References}

Isler, Ph. and B.M. Whitney (2002). Songs of the Antbirds. CD set. Macaulay Library of Natural Sounds. Cornell Lab. of Ornithology. Ithaca, NY.

Tobias, J.A., Seddon, N., Spottiswoode, C.N., Pilgrim, J.D., Fishpool, L.D.C. \& Collar, N.J. (2010). Quantitative criteria for species delimitation. Ibis 152(4): 724-746.

\section{Recommended citation}

Boesman, P. (2016). Notes on the vocalizations of Rufous Gnateater (Conopophaga lineata). HBW Alive Ornithological Note 66. In: Handbook of the Birds of the World Alive. Lynx Edicions, Barcelona. (retrieved from http://www.hbw.com/node/931950 on 15 May 2016). 